\title{
QUALIDADE FÍSICA DE UM LATOSSOLO VERMELHO, PERDAS POR EROSÃO E DESENVOLVIMENTO DO MILHO EM DOIS SISTEMAS DE MANEJO
}

\author{
Soil physical quality of a Rhodic Hapludox, erosion losses, and maize \\ development under two management systems
}

\author{
Sebastião Rovilson Marques' ${ }^{1}$, Mara de Andrade Marinho Weill², Laura Fernanda Simões da Silva ${ }^{1}$
}

\begin{abstract}
RESUMO
O manejo agrícola interfere nas condições físicas, químicas e biológicas do solo, na capacidade produtiva do sistema agrícola e na susceptibilidade do solo ao processo erosivo, não raramente acentuando-a. Objetivou-se, neste estudo, estudar a influência de dois sistemas de manejo sobre a qualidade física de um Latossolo Vermelho Distroférrico típico da região de Campinas, SP, bem como seus efeitos tanto no desenvolvimento e produtividade da cultura do milho, quanto no controle das perdas de terra e de nutrientes por erosão. Foram comparados dois sistemas de manejo, sistema plantio direto (SPD) e sistema convencional com grade aradora (SC), aplicando-os em parcelas experimentais dotadas com sistemas coletores de enxurrada para avaliação das perdas de terra e de nutrientes por erosão. Também foram analisados atributos físicos e químicos do solo, bem como dados biométricos e de produtividade da cultura do milho. Os resultados evidenciam que o manejo agrícola influenciou a qualidade do solo, sendo que os indicadores físicos foram melhores no sistema convencional. No entanto, os indicadores biométricos, em especial altura de plantas, foram superiores no sistema plantio direto. Também houve influência do manejo sobre o controle da erosão, ocorrendo maiores perdas de solo e de nutrientes, em particular, de fósforo e de matéria orgânica nas parcelas sob SC.
\end{abstract}

Termos para indexação: Sistema plantio direto, sistema convencional, compactação do solo, indicadores de qualidade.

\section{ABSTRACT}

Agricultural management influences the physical, chemical and biological conditions of the soil, affecting soil quality, the productivity capacity of the agricultural system and its vulnerability to erosion process, frequently increasing it. The purpose of this work was to study the influence of two agricultural management systems on physical soil quality of a Rhodic Hapludox occurring in Campinas, State of São Paulo, and their effects not only on corn crop development and yield, but also on soil and nutrient loss by erosion. Two management systems were compared, named direct drilling system (DDS) and conventional system (CS), by applying them in experimental plots having runoff collectors to assess soil and nutrient losses by erosion. Soil physical and chemical attributes were also analyzed, as well as biometrical and yield data of the corn crop. The results indicate that agricultural management has differently influenced soil quality, and that soil physical indicators were better under the conventional system (CS). However, biometrical indicators, especially plant height, were superior under direct drilling system (DDS). There was also influence of agricultural management on erosion control, occurring greater soil losses and particularly larger phosphorous and organic matter losses from plots under conventional system (CS).

Index terms: Direct drilling system, conventional system, soil compaction, quality indicators.

(Recebido em 19 de junho de 2008 e aprovado em 7 de abril de 2010)

\section{INTRODUÇÃO}

No contexto do uso agrícola sustentável, o manejo deve contribuir para a manutenção ou melhoria da qualidade do solo para produção de culturas, permitindo obter adequadas produtividades, com qualidade e segurança alimentar, em longo prazo (Doran \& Parkin, 1994).

A relação entre manejo agrícola e qualidade do solo pode ser avaliada pela caracterização e monitoramento de atributos físicos, químicos e biológicos do solo (Lal,
1999).Pôrto et al. (2009), estudando o efeito de diferentes sistemas de uso agrícola em indicadores biológicos de qualidade do solo, concluíram que todos os sistemas agrícolas provocaram perda da qualidade do solo, sendo mais pronunciada na área sob manejo mais intensivo. Dentre os atributos físicos, a estrutura é uma característica sensível ao manejo, mas que não pode ser avaliada diretamente. A estabilidade de agregados, a macroporosidade, a resistência do solo à penetração (índice de cone) e a densidade do solo figuram entre os atributos

\footnotetext{
${ }^{1}$ Universidade Federal de Campinas - Faculdade de Engenharia Agrícola - Campinas, SP

2 Universidade Federal de Campinas - Faculdade de Engenharia Agrícola - Área de Água e Solo - Avenida Cândido Rondon - 501 - Cx. P. 6011 - 13.083 875 - Campinas, SP - mweill@agr.unicamp.br
} 
mais comumente utilizados na avaliação da estrutura do solo (Cintra et al., 1983; Falleiro et al., 2003). O monitoramento desses atributos em áreas submetidas a diferentes sistemas de manejo possibilita a comparação dos efeitos de cada um e a interpretação acerca da adequabilidade do uso agrícola. No contexto do uso sustentável, é relevante eleger pelo menos uma variável resposta em relação à qual as comparações entre sistemas podem ser efetuadas. A avaliação das perdas de terra por erosão e do desenvolvimento e produtividade das culturas são critérios válidos na comparação da eficiência dos sistemas de produção.

Objetivou-se, no trabalho, verificar a influência do sistema plantio direto e do sistema convencional com grade aradora, sobre a qualidade de atributos físicos e químicos de um Latossolo Vermelho Distroférrico típico da região de Campinas (SP), sobre as perdas de solo por erosão e sobre o crescimento e produtividade da cultura do milho.

\section{MATERIAL E MÉTODOS}

O trabalho relata o primeiro ano de ensaio de campo, instalado em agosto de 2003, no Campo Experimental da Faculdade de Engenharia Agrícola da UNICAMP (Campinas, SP), em área de Latossolo Vermelho Distroférrico típico A moderado relevo ondulado (Rhodic Hapludox), declividade local de $0,09 \mathrm{~m} \mathrm{~m}^{-1}$. Esse solo caracteriza-se pela ocorrência de elevados teores de ferro total, herdados do material de origem, que é derivado do retrabalhamento de rochas básicas (Oliveira et al., 1979). É um solo profundo ou muito profundo, de textura argilosa ou muito argilosa, sendo o teor médio de argila de $610 \mathrm{~g} \mathrm{~kg}^{-1}$; a estrutura é forte, muito pequena granular, e a consistência, úmida, friável e muito friável.
O ensaio foi instalado em oito parcelas de $600 \mathrm{~m}^{2}$ cada, dotadas com sistemas coletores das perdas de terra e de água por erosão. Foram testados dois tratamentos, correspondentes aos sistemas de manejo convencional (grade aradora) e plantio direto, com quatro replicações. Antes da instalação do ensaio, em julho de 2003, foi efetuada amostragem para caracterização da condição física e de fertilidade do solo nas parcelas experimentais, finalizando ensaio anterior de longa duração, no qual cada parcela recebeu tratamento distinto quanto ao sistema de preparo do solo. Baseando-se nos resultados das análises de fertilidade e na produtividade potencial da cultura, fezse a determinação das necessidades de adubação e calagem. A caracterizarão da condição presente do solo, com base nos resultados da amostragem pré-ensaio constam do trabalho de Marques (2006). Para fins de informação da história de uso do solo na área experimental, são indicados no Quadro 1, os tratamentos aplicados a cada parcela no ensaio anterior e no ensaio atual.

Antes da implantação do ensaio atual, procedeuse à uma escarificação do solo em área total, a 0,30 m de profundidade, visando romper camadas compactadas e homogeneizar o solo das parcelas experimentais e da área entre as parcelas, minimizando os efeitos residuais decorrentes do ensaio anterior.

Ainda, anteriormente à semeadura da cultura principal (milho), foi semeada aveia preta, que foi mantida como planta de cobertura nas quatro parcelas sob SPD (P1 a P4), e incorporada ao solo nas quatro parcelas sob SC (P5 a P8), conforme Quadro 1. O milho foi semeado em 05 de novembro de 2003, empregando-se a variedade SHS 4050 da Santa Helena Sementes, um híbrido duplo, com tipo de grão duro, laranja, ciclo superprecoce, com

Quadro 1 - Descrição dos tratamentos do ensaio anterior e do ensaio atual na área das parcelas com sistemas coletores de enxurrada do Campo Experimental da FEAGRI. Campinas - SP.

\begin{tabular}{|c|c|c|}
\hline Parcela & $\begin{array}{c}\text { Tratamentos* } \\
\text { Ensaio Anterior }\end{array}$ & $\begin{array}{l}\text { Tratamentos } \\
\text { Ensaio Atual }\end{array}$ \\
\hline $\mathrm{P} 1$ & Grade Aradora & Sistema Plantio Direto (SPD) \\
\hline $\mathrm{P} 2$ & Sistema Alternado $^{1}$ & Sistema Plantio Direto (SPD) \\
\hline P3 & Escarificador & Sistema Plantio Direto (SPD) \\
\hline $\mathrm{P} 4$ & Semeadura Direta & Sistema Plantio Direto (SPD) \\
\hline P5 & Arado de Disco em Nível & Sistema Convencional (SC) \\
\hline P6 & Roçado $^{2}$ & Sistema Convencional (SC) \\
\hline P7 & Arado de Disco Morro Abaixo & Sistema Convencional (SC) \\
\hline P8 & Enxada Rotativa & Sistema Convencional (SC) \\
\hline
\end{tabular}

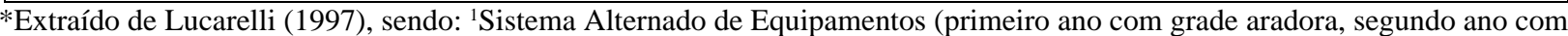
arado de discos, terceiro ano com arado de aivecas e quarto com escarificador); ${ }^{2}$ Parcela mantida Roçada sem Mobilização. 
florescimento masculino em 60 dias e maturação fisiológica média de 115 dias, com produtividade potencial de 8.245 $\mathrm{kg} \mathrm{ha}^{-1}$ ou de cerca de 138 sacos de $60 \mathrm{~kg}$ por hectare. A semeadura foi realizada com a densidade de plantio recomendada de 50.000 plantas ha $^{-1}$ (ou de 3.000 plantas por parcela de $600 \mathrm{~m}^{-2}$ ). Após a semeadura, cada parcela foi fechada enterrando-se placas metálicas, para que não houvesse entrada de águas pluviais de áreas adjacentes às parcelas, nem saída de água das parcelas. A adubação de cobertura foi efetuada aos 45 dias após o plantio. $\mathrm{O}$ florescimento do milho ocorreu no período entre 10 e 20 de janeiro e a colheita foi efetuada em março de 2004. Os tratos culturais foram realizados manualmente, seguindo os princípios dos respectivos sistemas de manejo.

Após o florescimento do milho, o solo de cada parcela foi amostrado para caracterização da fertilidade na profundidade de 0-0,20 m. Foram tomadas 15 amostras deformadas, sendo cinco a cada terço da parcela, que constituíram três amostras compostas por parcela. Foram determinados os seguintes atributos: $\mathrm{pH}$, em água e em $\mathrm{CaCl}_{2}$, pelo método potenciométrico, na relação 1:2,5; cálcio, magnésio, potássio e fósforo, pelo método de extração por resina trocadora de íons; sódio, pelo método do acetato de amônio $\mathrm{N}$ a pH 7,0; carbono orgânico, por oxidação via úmida com dicromato de potássio em meio sulfúrico; a acidez potencial $(\mathrm{H}+\mathrm{Al})$, pelo método do acetato de cálcio $\mathrm{N}$ a pH 7; alumínio trocável (Al), pelo método do $\mathrm{KCl} \mathrm{N}$, todos descritos em Raij et al. (2001).

Após a colheita do milho, foram coletadas amostras indeformadas em anéis volumétricos de cerca de $100 \mathrm{~cm}^{-3}$ ( $5 \mathrm{~cm}$ altura por $5 \mathrm{~cm}$ diâmetro interno). Em cada parcela, foram amostradas duas camadas do solo, nas profundidades entre $0,0-0,2 \mathrm{~m}$ (1) e $0,2-0,4 \mathrm{~m}$ (2), sendo que, na retirada das amostras, a parte central dos anéis foi localizada na profundidade média da camada, a $0,1 \mathrm{~m}$ e a $0,3 \mathrm{~m}$. Foram coletadas quinze amostras por camada por parcela experimental, cinco a cada terço, sendo determinadas a porosidade total, a macroporosidade, a microporosidade e a densidade do solo, conforme os métodos descritos em Empresa Brasileira de Pesquisa Agropecuária - Embrapa (1997). Também foram extraídas outras quinze amostras na camada de 0,0-0,2m, para análise da estabilidade de agregados pelo método do tamisamento via úmida, descrito em Kiehl (1979), sendo calculado o diâmetro médio ponderado dos agregados.

As perdas de terra por erosão foram determinadas diretamente por meio de sistemas coletores acoplados às parcelas experimentais, de acordo com método descrito por Mucthler et al. (1994). As coletas do material erodido foram realizadas manual e mensalmente, a partir do plantio e durante todo o ciclo da cultura até a colheita. Foram determinadas a massa seca total $(\mathrm{kg})$, a granulometria (teores de areia, silte e argila) e a fertilidade ( $\mathrm{pH} \mathrm{CaCl}_{2}$; matéria orgânica; teores de cálcio, magnésio, potássio e fósforo) do material erodido.

A avaliação do desenvolvimento do milho foi realizada a partir de ensaio biométrico da cultura, seguindo os procedimentos descritos por Duarte \& Paterniani (2000). Foram avaliadas 60 plantas por parcela, sendo contabilizados os valores do estande (número total de plantas), da altura das plantas (em) e da massa de 1.000 grãos (em kg).

A produtividade de cada parcela $\left(\mathrm{kg} \mathrm{ha}^{-1}\right)$ foi determinada colhendo-se manualmente toda a produção. Para cálculo das produtividades, retiraram-se amostras para determinação da umidade do grão, sendo que os valores foram padronizados para a umidade de $14,5 \%$, aplicandose a equação 1 (Duarte \& Paterniani, 2000):

$P_{f}=\left[P_{i}\left(100-\varpi_{i}\right)\right] /\left(100-\varpi_{f}\right)$

Sendo: $\mathrm{P}_{\mathrm{f}}=$ Massa final corrigida para a umidade de $14,5 \%$; $\mathrm{P}_{\mathrm{i}}=$ Massa inicial; $\varpi_{\mathrm{i}}=$ Umidade inicial determinada em laboratório; $\varpi_{\mathrm{f}}=$ Umidade final padrão de 14,5\%

Ainda, tendo sido constatada desuniformidade dos estandes, foi realizada análise de covariância para eliminação do efeito dessa fonte de variação sobre os dados de produtividade de cada parcela. Por se tratar do primeiro ano de ensaio implantado em área que vinha sendo utilizada há mais de vinte anos com diferentes sistemas de preparo do solo, os dados de cada parcela foram analisados separadamente. Foi realizada análise exploratória dos dados para cálculo dos momentos estatísticos dos diferentes atributos avaliados, empregando o método não-paramétrico de Kruskal-Wallis para verificação das diferenças entre médias das parcelas, duas a duas. Posteriormente foi empregado o teste de Man-Whitney, com 5\% de probabilidade, para testar a significância das diferenças entre médias. As análises estatísticas foram efetuadas utilizando o programa SAS (SAS Institute, 1999).

\section{RESULTADOS E DISCUSSÃO}

Os valores médios de porosidade total, macroporosidade, microporosidade e densidade do solo nas profundidades de $0,0-0,2 \mathrm{~m}$ e de $0,2-0,4 \mathrm{~m}$ estão apresentados no Quadro 2. Na profundidade 0,0-0,2m, a porosidade total nas parcelas P7 e P8, manejadas sob sistema convencional (SC) é significativamente superior aos valores das demais parcelas. A elevada porosidade total no solo da parcela P8, de cerca de $58 \%$, pode estar refletindo o efeito residual do uso prolongado de enxada 
rotativa no preparo do solo do ensaio anterior realizado na área (Quadro 1). Em todas as parcelas, no entanto, a porosidade total é inferior àquela do solo sob mata (referência perfil 1245 do trabalho de Oliveira \& Menk (1984)), cujo valor é de $0,63 \mathrm{~m}^{3} \mathrm{~m}^{-3}$ na camada $0,0-0,35 \mathrm{~m}$, confirmando o efeito do manejo agrícola no sentido da redução da Pt. A porosidade total é ainda mais baixa na profundidade $0,2-0,4 \mathrm{~m}$, variando entre 0,45 e $0,51 \mathrm{~m}^{3} \mathrm{~m}^{-3}$. As diferenças são significativas apenas entre as parcelas P4 (SPD), que detém o menor valor, de $0,45 \mathrm{~m}^{3} \mathrm{~m}^{-3}$, e P8 (SC), com o maior valor de $0,51 \mathrm{~m}^{3} \mathrm{~m}^{-3}$, não ocorrendo diferenças significativas quanto a esse atributo entre as demais parcelas.

Os valores médios de micro e de macroporosidade do Quadro 2 indicam que a redução da Pt na camada 1 ocorreu às custas da diminuição da macroporosidade (Mac), uma vez que o solo das parcelas não difere quanto à microporosidade. Esse comportamento corrobora com as constatações de Silva \& Kay (1997) de que a microporosidade do solo é fortemente influenciada pela granulometria e pelo teor de carbono orgânico e muito pouco influenciada pelo aumento da densidade do solo decorrente do tráfego de máquinas e implementos, justificando a similaridade de microporosidade entre os tratamentos.

Os maiores valores de Mac ocorreram nas parcelas P8 e P7, sendo que o valor de $\mathrm{Mac}=0,20 \mathrm{~m}^{3} \mathrm{~m}^{-3}$ da parcela P8 diferiu estatisticamente de todos os demais, no nível de $5 \%$ de probabilidade. Em seis parcelas o volume de macroporos aproxima-se da porosidade mínima de aeração requerida ou valor crítico de $\mathrm{P}_{\mathrm{A}}=0,10 \mathrm{~m}^{3} \mathrm{~m}^{-3}$ (Xu et al., 1992), indicativo da ocorrência de limitações da qualidade estrutural do solo relacionadas com deficiência de oxigênio para as raízes. No caso da parcela P3, manejada sob SPD no ensaio atual e com escarificador no ensaio anterior, a porosidade de aeração estimada como sendo de $0,09 \mathrm{~m}^{3} \mathrm{~m}^{-3}$ está abaixo do valor crítico. Os resultados indicam que as restrições quanto à disponibilidade de oxigênio devem aumentar na profundidade $0,2-0,4 \mathrm{~m}$, uma vez que, na maioria das parcelas, a porosidade de aeração é igual ou inferior à porosidade de aeração crítica. Apenas nas parcelas P6 e P8, a porosidade de aeração é significativamente maior do que $0,10 \mathrm{~m}^{3} \mathrm{~m}^{-3}$.

Com relação à densidade do solo, há pequena diferenciação entre parcelas na profundidade $0,0-0,2 \mathrm{~m}$, nesse primeiro ano de instalação do ensaio. Diferenças significativas ocorrem apenas entre as parcelas P1 (Ds = 1,36 $\left.\mathrm{kg} \mathrm{dm}^{-3}\right)$, P7 $\left(1,3 \mathrm{~kg} \mathrm{dm}^{-3}\right)$ e P8 $\left(1,2 \mathrm{~kg} \mathrm{dm}^{-3)}\right.$, todos valores altos em comparação com a Ds do perfil de referência, de $0,95 \mathrm{~kg} \mathrm{dm}^{-3}$ na profundidade $0,0-0,35 \mathrm{~m}$. Para a profundidade $0,2-0,4 \mathrm{~m}$, os valores de Ds seguem a mesma tendência da camada superior sendo, no entanto, ainda mais elevados, especialmente nas parcelas P1, P2 e P3 onde se aproximam de $1,4 \mathrm{~kg} \mathrm{dm}^{-3}$, valor muito alto tendo em vista a granulometria argilosa e muito argilosa do solo, indicativo de compactação. Em sua condição natural, no perfil do solo sob mata (referência), a Ds em profundidade $(0,68-1,20 \mathrm{~m})$ é a mesma da camada superficial, de apenas $0,95 \mathrm{~kg} \mathrm{dm}^{-3}$.

O Quadro 3 relaciona os resultados da análise de estabilidade de agregados da camada superficial do solo (0,0-0,2m), destacando-se o diâmetro médio ponderado (DMP) dos agregados do solo em cada parcela, e a distribuição porcentual de solo retido em cada classe de tamanho de peneira.

Quadro 2 - Valores médios dos atributos físicos do solo: Porosidade total (Pt), Microporosidade (Mic), Macroporosidade (Mac) e Densidade do solo (Ds) nas camadas 0,0-0,2m (1) e 0,2-0,4m (2).

\begin{tabular}{|c|c|c|c|c|c|c|c|c|c|}
\hline \multirow{3}{*}{ Parcela } & \multirow{3}{*}{ Tratamento } & \multicolumn{2}{|c|}{ Porosidade Total } & \multirow{2}{*}{\multicolumn{2}{|c|}{$\frac{\text { Macroporosidade }}{\mathrm{m}^{3} \mathrm{~m}^{-3}}$}} & \multicolumn{2}{|c|}{ Microporosidade } & \multirow{2}{*}{\multicolumn{2}{|c|}{$\frac{\text { Densidade do solo }}{\mathrm{kg} \mathrm{dm}^{-3}}$}} \\
\hline & & & & & & & & & \\
\hline & & 1 & 2 & 1 & 2 & 1 & 2 & 1 & 2 \\
\hline P1 & SPD & $0,51^{\mathrm{A}}$ & $0,47^{\mathrm{ABC}}$ & $0,11^{\mathrm{BC}}$ & $0,10^{\mathrm{A}}$ & $0,39^{\mathrm{A}}$ & $0,37^{\mathrm{ABCD}}$ & $1,36^{\mathrm{A}}$ & $1,38^{\mathrm{AB}}$ \\
\hline $\mathrm{P} 2$ & SPD & $0,50^{\mathrm{A}}$ & $0,46^{\mathrm{ABC}}$ & $0,10^{\mathrm{B}}$ & $0,09^{\mathrm{A}}$ & $0,39^{\mathrm{A}}$ & $0,37^{\mathrm{ABCD}}$ & $1,34^{\mathrm{A}}$ & $1,38^{\mathrm{AB}}$ \\
\hline P3 & SPD & $0,48^{\mathrm{BC}}$ & $0,46^{\mathrm{ABC}}$ & $0,09^{\mathrm{B}}$ & $0,09^{\mathrm{A}}$ & $0,38^{\mathrm{A}}$ & $0,36^{\mathrm{ABCD}}$ & $1,35^{\mathrm{AB}}$ & $1,39^{\mathrm{A}}$ \\
\hline P4 & SPD & $0,49^{\mathrm{AB}}$ & $0,45^{\mathrm{B}}$ & $0,11^{\mathrm{B}}$ & $0,09^{\mathrm{A}}$ & $0,38^{\mathrm{A}}$ & $0,35^{\mathrm{B}}$ & $1,34^{\mathrm{AB}}$ & $1,35^{\mathrm{ABC}}$ \\
\hline P5 & $\mathrm{SC}$ & $0,49^{\mathrm{AB}}$ & $0,47^{\mathrm{C}}$ & $0,11^{\mathrm{B}}$ & $0,10^{\mathrm{A}}$ & $0,37^{\mathrm{A}}$ & $0,36^{\mathrm{C}}$ & $1,34^{\mathrm{AB}}$ & $1,33^{\mathrm{BC}}$ \\
\hline P6 & $\mathrm{SC}$ & $0,50^{\mathrm{A}}$ & $0,47^{\mathrm{AC}}$ & $0,11^{\mathrm{AB}}$ & $0,12^{\mathrm{B}}$ & $0,39^{\mathrm{A}}$ & $0,36^{\mathrm{BC}}$ & $1,32^{\mathrm{AB}}$ & $1,32^{\mathrm{CD}}$ \\
\hline P7 & $\mathrm{SC}$ & $0,53^{\mathrm{D}}$ & $0,47^{\mathrm{AC}}$ & $0,14^{\mathrm{ACD}}$ & $0,10^{\mathrm{A}}$ & $0,38^{\mathrm{A}}$ & $0,37^{\mathrm{D}}$ & $1,30^{\mathrm{B}}$ & $1,31^{\mathrm{D}}$ \\
\hline P8 & $\mathrm{SC}$ & $0,57^{\mathrm{E}}$ & $0,51^{\mathrm{D}}$ & $0,20^{\mathrm{E}}$ & $0,15^{\mathrm{C}}$ & $0,38^{\mathrm{A}}$ & $0,36^{\mathrm{ABCD}}$ & $1,20^{\mathrm{C}}$ & $1,23^{\mathrm{F}}$ \\
\hline
\end{tabular}

1- camada 0,0-0,2m; 2- camada 0,2-0,4m. Médias seguidas de mesma letra maiúscula, não diferem entre si ao nível de $5 \%$ de probabilidade, pelo teste de Man-Whitney 
Quadro 3 - Diâmetro médio ponderado (DMP) dos agregados do solo na camada 0,0-0,2m e distribuição dos agregados por classe de tamanho, sob dois sistemas de manejo do solo.

\begin{tabular}{|c|c|c|c|c|c|c|c|c|}
\hline \multirow{3}{*}{ Parcela } & \multirow{3}{*}{ Tratamento } & \multirow{3}{*}{$\begin{array}{l}\text { Diâmetro Médio } \\
\text { Ponderado } \\
\text { (DMP, mm) }\end{array}$} & \multicolumn{6}{|c|}{ Classes de tamanho (mm) } \\
\hline & & & $<0,125$ & $0,125-0,25$ & $0,25-0,5$ & $0,5-1,0$ & $1,0-2,0$ & $>2,0$ \\
\hline & & & \multicolumn{6}{|c|}{ Solo retido na peneira em relação ao total analisado (\%) } \\
\hline $\mathrm{P} 1$ & SPD & $2,68^{\mathrm{BC}}$ & 3 & 5 & 7 & 13 & 18 & 54 \\
\hline $\mathrm{P} 2$ & SPD & $2,50^{\mathrm{CD}}$ & 4 & 6 & 10 & 15 & 16 & 50 \\
\hline $\mathrm{P} 3$ & SPD & $2,95^{\mathrm{B}}$ & 2 & 3 & 6 & 11 & 15 & 62 \\
\hline P4 & SPD & $2,50^{\mathrm{CD}}$ & 4 & 5 & 9 & 15 & 18 & 49 \\
\hline P5 & $\mathrm{SC}$ & $2,32^{\mathrm{DE}}$ & 4 & 6 & 10 & 16 & 20 & 44 \\
\hline P6 & $\mathrm{SC}$ & $3,39^{\mathrm{A}}$ & 2 & 2 & 4 & 6 & 11 & 76 \\
\hline P7 & $\mathrm{SC}$ & $2,00^{\mathrm{E}}$ & 6 & 9 & 14 & 17 & 17 & 37 \\
\hline P8 & SC & $2,25^{\mathrm{D}}$ & 5 & 6 & 10 & 16 & 19 & 43 \\
\hline
\end{tabular}

Médias seguidas de mesma letra maiúscula, não diferem entre si ao nível de $5 \%$ de probabilidade, pelo teste de Man-Whitney

O maior valor de DMP, de $3,39 \mathrm{~mm}$, ocorreu no solo da parcela P6, manejada sob SC, sendo que $76 \%$ dos agregados são maiores do que $2,0 \mathrm{~mm}$. Considerando que o solo dessa parcela foi mantido sob gramínea por longo período, sendo apenas roçado (Quadro 1), tal resultado pode ser indicativo de efeito residual positivo do ensaio anterior. Melhor agregação do solo proporcionada pelo sistema radicular das gramíneas já foi relatada por Dechen et al. (1981), Silva \& Mielniczuk (1997) e Costa et al. (2008), que observaram a grande influência das raízes na formação e estabilidade dos agregados do solo. Os outros dois maiores valores de DMP ocorreram no solo das parcelas P3 $(2,95 \mathrm{~mm})$ e P1 $(2,68 \mathrm{~mm})$, ambas manejadas sob SPD e com maior porcentual de agregados dentro da classe acima de $2,00 \mathrm{~mm}$ de diâmetro. Lucarelli (1997), que trabalhou na mesma área, constatou para a camada $0,00-0,20 \mathrm{~m}$ que o valor médio do DMP dos agregados provenientes dos tratamentos com menor mobilização do solo (conservacionistas) foi superior ao daqueles com maior mobilização (convencionais).

Tais resultados indicam que apesar dos indicadores de qualidade física Pt, Mac e Ds indicarem pior condição do solo nas parcelas manejadas sob SPD, a análise de estabilidade de agregados indica a ocorrência de grandes agregados estáveis nessas mesmas parcelas, significativamente maiores do que os agregados das parcelas manejadas sob SC.

Aparentemente conflitantes, os dados revelam que, embora internamente aos agregados o solo das parcelas manejadas sob SPD esteja aparentemente compactado, há suficiente porosidade entreagregados devido à presença majoritária de grandes agregados estáveis, garantindo a necessária aeração do solo e a adequada disponibilidade de oxigênio às raízes. Os resultados da análise biométrica e de produtividade do milho (Quadro 4) indicam que a altura das plantas manejadas sob SPD foi significativamente superior ou não diferiu da altura das plantas manejadas sob SC, indicativo de que a planta de fato não encontrou limitações para crescer, a despeito dos indicadores Mac e Ds indicarem o contrário. Tais resultados são concordantes com aqueles apresentados por Moody et al. (1961), que observaram maior taxa de crescimento do milho sob SPD do que sob SC.

Conquanto não tenham sido caracterizadas diferenças significativas entre parcelas para massa de 1000 grãos e produtividade, nas parcelas sob SPD, os valores são semelhantes ou superiores à produtividade potencial esperada da variedade de cerca de $8.200 \mathrm{~kg} \mathrm{ha}^{-1}$, o que também indica ausência de possíveis limitações ao desenvolvimento da cultura.

Resumindo, a presença de grandes agregados, estáveis no solo das parcelas sob SPD, conferiu adequada porosidade de aeração e penetrabilidade às raízes do milho, cujas plantas se desenvolveram tanto quanto ou mais do que nas parcelas sob SC, a despeito dos valores de $\mathrm{Pt}, \mathrm{P}_{\mathrm{A}}$ e Ds indicarem pior condição física do solo sob SPD. Tal constatação revela a importância da análise integrada de diferentes indicadores na avaliação da qualidade estrutural do solo e a utilidade de se considerar uma variável resposta (no caso, o desenvolvimento e produtividade da cultura) em relação à qual os sistemas de manejo possam ser comparados.

O Quadro 5 relaciona as perdas de terra por erosão, em kg ha ${ }^{-1}$,coletadas no período entre 05/12/2003 e 08/03/ 2004, durante a safra de milho no primeiro ano de instalação do ensaio. Os resultados indicam que as menores perdas de solo, de $206 \mathrm{~kg} \mathrm{ha}^{-1}$, ocorreram na parcela P1 (SPD), seguida por P6 (SC) < P2 (SPD), que perderam em média $263 \mathrm{~kg} \mathrm{ha}^{-1}$. Em P4 (SPD) e P5 (SC), as perdas foram da ordem de $516 \mathrm{~kg}$ $\mathrm{ha}^{-1}$, atribuindo-se a perda relativamente elevada da parcela 
P4, à ocorrência de falhas na cobertura morta, na parte inferior dessa parcela. Perdas de terra muito acentuadas foram observadas nas parcelas P7 e P8, ambas sob SC.

Considerando-se o total acumulado por época de avaliação em cada sistema de manejo, notam-se perdas menores nas parcelas manejadas sob SPD (Quadro 5). Para os dois sistemas, as perdas diminuem com o desenvolvimento da cultura, devido ao aumento da cobertura vegetal e maior proteção do solo. Anteriormente, o efeito do estádio de desenvolvimento do milho sobre as perdas por erosão foi relatado por Margolis et al. (1980), que relataram que as mesmas decresceram com o desenvolvimento da cultura, devido ao aumento da massa foliar e consequente aumento da proteção do solo contra o impacto das gotas de chuva.

Em termos médios, as perdas totais de terra nas parcelas sob SPD corresponderam a apenas $20 \%$ das ocorridas nas parcelas sob SC. Schick et al. (2000) também constataram que o SPD foi mais eficaz no controle da erosão do solo, com perdas de terra $68 \%$ menores em relação àquelas observadas para o preparo convencional com uma aração seguida de duas gradagens.

Quanto à fertilidade do solo, não ocorreram diferenças significativas entre parcelas para os valores de $\mathrm{pH}$, cálcio, magnésio, potássio, matéria orgânica e saturação por bases. Tal resultado era esperado, dado que a adubação foi realizada para corrigir as deficiências do solo quanto às exigências da cultura, e positivo, pois a fertilidade do solo não deveria mesmo ser uma fonte de variação do ensaio. Mas, quanto às perdas de nutrientes no material erodido, as de fósforo e de matéria orgânica foram muito maiores no SC (Figura 1). Hernani et al. (1999) também constataram que o SPD foi mais eficaz no controle da erosão, condicionando menores perdas totais de nutrientes e de matéria orgânica do solo.

Quadro 4 - Dados biométricos e de produtividade da cultura do milho sob dois sistemas de manejo agrícola, em área de Latossolo Vermelho Distroférrico típico. Campinas -(SP).

\begin{tabular}{|ccccc|}
\hline Parcela & Tratamento & Altura das Plantas $(\mathrm{cm})$ & Massa de 1000 grãos $(\mathrm{g})$ & Produtividade $\left(\mathrm{kg} \mathrm{ha}^{-1}\right)$ \\
\hline P1 & SPD & $246,0^{\mathrm{BC}}$ & $420,7^{\mathrm{A}}$ & $8.488,7^{\mathrm{A}}$ \\
P2 & SPD & $236,1^{\mathrm{D}}$ & $375,5^{\mathrm{A}}$ & $8.160,8^{\mathrm{A}}$ \\
P3 & SPD & $237,0^{\mathrm{D}}$ & $400,6^{\mathrm{A}}$ & $8.070,6^{\mathrm{A}}$ \\
P4 & SPD & $258,7^{\mathrm{A}}$ & $389,6^{\mathrm{A}}$ & $10.9741,1^{\mathrm{A}}$ \\
P5 & SC & $236,0^{\mathrm{D}}$ & $360,6^{\mathrm{A}}$ & $7.891,9^{\mathrm{A}}$ \\
P6 & SC & $249,3^{\mathrm{B}}$ & $338,6^{\mathrm{A}}$ & $8.157,5^{\mathrm{A}}$ \\
P7 & SC & $237,9^{\mathrm{CD}}$ & $364,7^{\mathrm{A}}$ & $7.733,0^{\mathrm{A}}$ \\
P8 & SC & $231,6^{\mathrm{D}}$ & $329,1^{\mathrm{A}}$ & $7.546,7^{\mathrm{A}}$ \\
\hline
\end{tabular}

Médias seguidas de mesma letra maiúscula na coluna não diferem entre si no nível de $5 \%$ de probabilidade, pelo teste de Man-Whitney

Quadro 5 - Perdas de solo por erosão nas parcelas experimentais, no período entre 05/11/2003 e 08/03/2004 (safra de milho).

\begin{tabular}{|ccccccccc|}
\hline \multicolumn{2}{|c}{ Período } & $\begin{array}{c}5 / 11 / 03 \mathrm{a} \\
5 / 12 / 2003\end{array}$ & $\begin{array}{c}5 / 12 / 03 \mathrm{a} \\
5 / 1 / 2004\end{array}$ & $\begin{array}{c}5 / 1 / 04 \mathrm{a} \\
5 / 2 / 2004\end{array}$ & $\begin{array}{c}5 / 2 / 04 \mathrm{a} \\
8 / 3 / 2004\end{array}$ & $\begin{array}{c}\text { Total no } \\
\text { Período }\end{array}$ & Média \\
\hline Parcela & Tratamento & \multicolumn{7}{c}{ Perdas de terra por erosão, $\mathrm{kg} \mathrm{ha}^{-1}$} \\
\hline P1 & SPD & 70 & 86 & 32 & 17 & 206 & 52 \\
P2 & SPD & 85 & 116 & 64 & 16 & 281 & 70 \\
P3 & SPD & 307 & 147 & 76 & 19 & 549 & 137 \\
P4 & SPD & 154 & 145 & 167 & 17 & 483 & 121 \\
\hline Total SPD & & 617 & 495 & 339 & 68 & 1519 & 95 \\
\hline P5 & SC & 414 & 275 & 98 & 24 & 811 & 203 \\
P6 & SC & 56 & 128 & 47 & 15 & 246 & 61 \\
P7 & SC & 403 & 2223 & 68 & 26 & 2720 & 680 \\
P8 & SC & 737 & 3474 & 346 & 87 & 4643 & 1161 \\
\hline Total SC & & 1610 & 6100 & 558 & 125 & 8394 & 526 \\
\hline
\end{tabular}




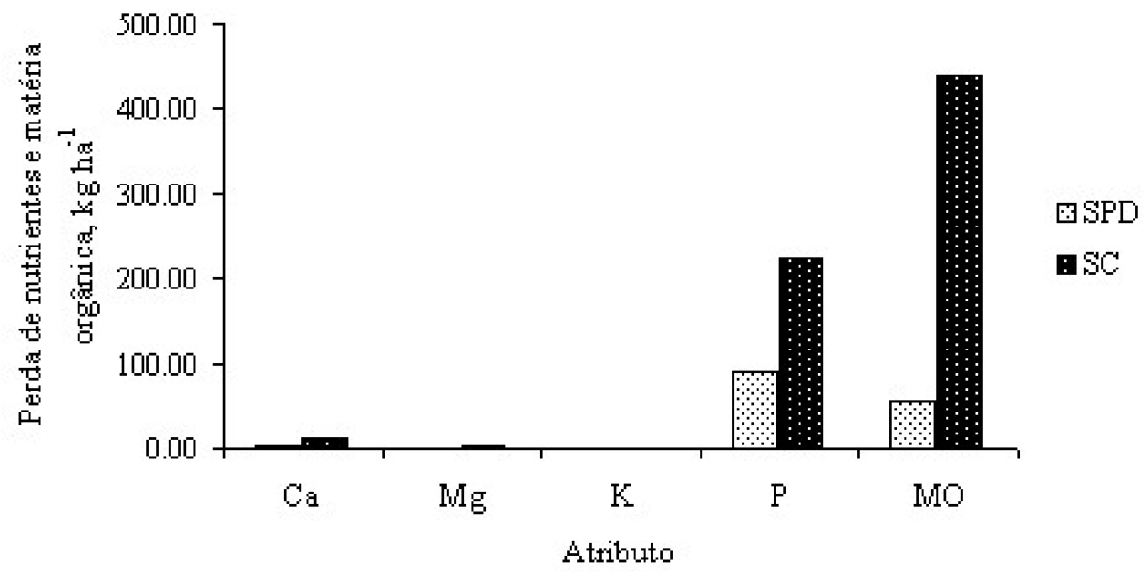

Figura 1 - Perdas totais de nutrientes por sistema de manejo, no período de avaliação do ensaio, sendo SPD- Sistema Plantio Direto e SC- Sistema Convencional.

Em síntese, na comparação dos dois sistemas de manejo, a avaliação qualitativa e quantitativa das perdas de terra por erosão foi útil para demonstrar que o SPD contribuiu para a manutenção ou melhoria da qualidade do solo, em função da economia de nutrientes e conservação da matéria orgânica observada no solo manejado sob esse sistema.

\section{CONCLUSÕES}

O manejo agrícola influenciou diferentemente atributos físicos do solo, atributos biométricos do milho e as perdas por erosão. Os melhores índices físicos de qualidade do solo ocorreram nas parcelas manejadas sob sistema convencional. O sistema plantio direto foi superior em relação aos indicadores de desenvolvimento da cultura e no controle das perdas de terra e de nutrientes por erosão, particularmente de fósforo e de matéria orgânica.

\section{REFERÊNCIAS BIBLIOGRÁFICAS}

CINTRA, F.L.D.; MIELNICZUK, J.; SCOPEL, I. Caracterização do impedimento mecânico em um latossolo roxo do Rio Grande do Sul. Revista Brasileira de Ciência do Solo, Campinas, v.7, p.323-327, 1983.

COSTA, A. M. da; RIBEIRO, B. T.; SILVA, A. de A.; BORGES, E. N. Estabilidade de agregados de um Latossolo Vermelho tratado com cama de peru. Ciência e Agrotecnologia, Lavras, v.32, n.1, p. 73-79, jan./fev., 2008.

DECHEN, S.C.F.; LOMBARDI NETO, F.; CASTRO, O.M. de. Gramíneas e leguminosas e seus restos culturais no controle da erosão em latossolo roxo. Revista

Brasileira de Ciência do Solo, Campinas, v.5, p.133137, 1981.

DORAN, J.W.; PARKIN, B.T. Defining and assessing soil quality. In: Soil Science Society of

America. Madison: SSSA, 1994. p. 3-22.

DUARTE, A.P.; PATERNIANI, M.E.A.G.Z. (Coord.). Fatores bióticos e abióticos em cultivares de milho e estratificação ambiental: avaliação IAC/CATI/Empresas 1999/2000. Campinas: Instituto Agronômico de Campinas, 2000. 150p. (Boletim científico, 5).

\section{EMPRESA BRASILEIRA DE PESQUISA} AGROPECUÁRIA. Manual de métodos de análise de solo. 2.ed. Rio de Janeiro: Centro Nacional de Pesquisa de Solos, 1997. 212p. (Documento, 1).

FALLEIRO, R.M.; SOUZA, C.M.; SILVA, C.S.W.; SEDIYAMA, C.S.; SILVA, A.A.; FAGUNDES, J.L. Influência dos sistemas de preparo nas propriedades químicas e físicas do solo. Revista Brasileira de Ciência do Solo, Viçosa, v.27, n.6, p.1097-1104, 2003.

HERNANI, L.C.; KURIHARA, C.H.; SILVA, W.M. Sistemas de manejo de solo e perdas de nutrientes e matéria orgânica por erosão. Revista Brasileira de Ciência do Solo, Viçosa, v.23, p.145-154, 1999.

KIEHL, E.J. Manual de edafologia: relação solo-planta. São Paulo: Agronômica Ceres, 1979. 262p. 
LAL, R. Métodos para avaliação do uso sustentável dos recursos solo e água nos trópico. Jaguariúna: Embrapa Meio Ambiente, 1999. 97p.

LUCARELLI, J.R. de F. Alterações em características de um latossolo roxo submetido a diferentes sistemas de manejo. 1997. 87p. Dissertação (Mestrado em Engenharia Agrícola)- Faculdade de Engenharia Agrícola, Universidade Estadual de Campinas, 1997.

MARGOLIS, E.; MELLO NETTO, A.V. de; ANDRADE, J.E. de P.; SILVA, A.B. da. Efeito do estádio de desenvolvimento da cultura do milho sobre as perdas por erosão. Revista Brasileira de Ciência do Solo, Campinas, v.4, p.193-195, 1980.

MARQUES, S.R. Sistemas de manejo agrícola, qualidade do solo e o controle da erosão em parcelas experimentais. 2006. 108p. Dissertação (Mestrado em Engenharia Agrícola)-Universidade Estadual de Campinas, Campinas, 2006.

MOODY, E.; SKEAR, G.M.; JONES, J.N. Growing corn without tillage. Proceedings of Soil Science Society of America, Madison, v.25, p.516-517, 1961.

OLIVEIRA, J.B.; MENK, J.R.F. Latossolos roxos do estado de São Paulo. Campinas: Instituto Agronômico, 1984. 82p. (Boletim técnico, 82).

OLIVEIRA, J.B.; MENK, J.R.F.; ROTTA, C.L. Levantamento pedológico semidetalhado dos solos do estado de São Paulo: quadrícula de Campinas. Rio de Janeiro: IBGE, 1979. 169p. (Série Recursos Naturais e Meio Ambiente, 5).

PÔRTO, M. L.; ALVES, J. do C.; DINIZ, A. A.; SOUZA, A. P. de; SANTOS, D. Indicadores biológicos de qualidade do solo em diferentes sistemas de uso no brejo paraibano. Ciência e Agrotecnologia, Lavras, v.33, n.4, p. 1011-1017, jul./ago., 2009.

RAIJ, B. van; ANDRADE, J.C. de; CANTARELLI, H.; QUAGGIO, J.A. Análise química para avaliação de fertilidade de solos tropicais. Campinas: Instituto Agronômico de Campinas, 2001. 285p.

SAS INSTITUTE. SAS/STAT: user's guide. Version 8. Cary, 1999. 50p.

SCHICK et al. Erosão hídrica em cambissolo húmico alumínico submetido a diferentes sistemas de preparo e cultivo do solo: I., perdas de solo e água. Revista Brasileira de Ciência do Solo, Viçosa, v.24, n.2, p.427436, 2000.

SILVA, L. de F. da; MIELNICZUK, J. Ação do sistema radicular de plantas na formação e estabilização de agregados no solo. Revista Brasileira de Ciência do Solo, Campinas, v.21, n.1, p.113-117, 1997.

XU, L.; SWAN, J.B.; PAULSON, W.H.; RANDALL, G.W. Tillage effects on measured soil hydraulic properties. Soil Tillage Research, Amsterdam, v.25, p.17-33, 1992. 